\title{
Statistical-dynamical downscaling for wind energy potentials: evaluation and applications to decadal hindcasts and climate change projections
}

Article

Published Version

Reyers, M., Pinto, J. G. and Moemken, J. (2015) Statisticaldynamical downscaling for wind energy potentials: evaluation and applications to decadal hindcasts and climate change projections. International Journal of Climatology, 35 (2). pp. 229-244. ISSN 0899-8418 doi:

https://doi.org/10.1002/joc.3975 Available at https://centaur.reading.ac.uk/37937/

It is advisable to refer to the publisher's version if you intend to cite from the work. See Guidance on citing.

Published version at: http://dx.doi.org/10.1002/joc.3975

To link to this article DOI: http://dx.doi.org/10.1002/joc.3975

Publisher: John Wiley \& Sons

All outputs in CentAUR are protected by Intellectual Property Rights law, including copyright law. Copyright and IPR is retained by the creators or other copyright holders. Terms and conditions for use of this material are defined in the End User Agreement. 


\section{www.reading.ac.uk/centaur}

\section{CentAUR}

Central Archive at the University of Reading

Reading's research outputs online 


\title{
Statistical-dynamical downscaling for wind energy potentials: evaluation and applications to decadal hindcasts and climate change projections
}

\author{
Mark Reyers, ${ }^{\text {a* }}$ Joaquim G. Pinto ${ }^{\mathrm{a}, \mathrm{b}}$ and Julia Moemken ${ }^{\mathrm{a}}$ \\ ${ }^{a}$ Institute for Geophysics and Meteorology, University of Cologne, Germany \\ ${ }^{\mathrm{b}}$ Department of Meteorology, University of Reading, UK
}

\begin{abstract}
A statistical-dynamical downscaling (SDD) approach for the regionalization of wind energy output $\left(E_{\text {out }}\right)$ over Europe with special focus on Germany is proposed. SDD uses an extended circulation weather type (CWT) analysis on global daily mean sea level pressure fields with the central point being located over Germany. Seventy-seven weather classes based on the associated CWT and the intensity of the geostrophic flow are identified. Representatives of these classes are dynamically downscaled with the regional climate model COSMO-CLM. By using weather class frequencies of different data sets, the simulated representatives are recombined to probability density functions (PDFs) of near-surface wind speed and finally to $E_{\text {out }}$ of a sample wind turbine for present and future climate. This is performed for reanalysis, decadal hindcasts and long-term future projections. For evaluation purposes, results of SDD are compared to wind observations and to simulated $E_{\text {out }}$ of purely dynamical downscaling (DD) methods.

For the present climate, SDD is able to simulate realistic PDFs of 10-m wind speed for most stations in Germany. The resulting spatial $E_{\text {out }}$ patterns are similar to DD-simulated $E_{\text {out }}$. In terms of decadal hindcasts, results of SDD are similar to DD-simulated $E_{\text {out }}$ over Germany, Poland, Czech Republic, and Benelux, for which high correlations between annual $E_{\text {out }}$ time series of SDD and DD are detected for selected hindcasts. Lower correlation is found for other European countries. It is demonstrated that SDD can be used to downscale the full ensemble of the Earth System Model of the Max Planck Institute (MPI-ESM) decadal prediction system.

Long-term climate change projections in Special Report on Emission Scenarios of ECHAM5/MPI-OM as obtained by SDD agree well to the results of other studies using DD methods, with increasing $E_{\text {out }}$ over northern Europe and a negative trend over southern Europe. Despite some biases, it is concluded that SDD is an adequate tool to assess regional wind energy changes in large model ensembles.
\end{abstract}

KEY WORDS wind energy; statistical-dynamical downscaling; decadal forecasts; climate change projections; ensembles

Received 11 November 2013; Revised 10 January 2014; Accepted 11 February 2014

\section{Introduction}

In recent years, the demand for renewable energy sources as alternative to fossil sources has increased due to the imperative need to reduce greenhouse gas emissions (Solomon et al., 2007). In Europe, wind energy production has emerged as a promising energy source to mitigate the climate change resulting from anthropogenic greenhouse gas emission. A main challenge for political and economical decision makers is the installation of an effective network of wind power plants (Manwell et al., 2009; Wilkes et al., 2012) to meet the goal of the European Commission to produce $15.7 \%$ of the EU's electricity usage from wind energy resources by 2020 (Moccia et al., 2011).

Near-surface winds, and thus wind energy production, strongly depend on the synoptic scale variability

\footnotetext{
* Correspondence to: M. Reyers, Institute for Geophysics and Meteorology, University of Cologne, Pohligstr. 3, 50923 Cologne, Germany. E-mail: mreyers@meteo.uni-koeln.de
}

(2-6 days, e.g. passage of low- and high-pressure centres), seasonality, and on climate variability on different timescales (e.g. Pryor and Barthelmie, 2010). Furthermore, conditions for wind energy production are strongly influenced by local characteristics (e.g. Ouammi et al., 2012). Hence, suitable predictions of regional changes of wind energy potentials on inter-annual to decadal and on centennial timescales are essential for future planning.

A set of global decadal prediction hindcasts have been recently made available through the Coupled Model Intercomparison Project Phase 5 (CMIP5; Taylor et al., 2012). In these experiments, initial conditions for decadal hindcasts and predictions are taken from assimilation runs using analysis data from the past and present for the relaxation towards gridded observational values. Since small initialization perturbations, which reflect the observational uncertainties, might rapidly grow, differences between ensemble members may be large because of these uncertainties (Merryfield et al., 2013). Therefore, large ensembles of decadal hindcasts are required for the assessment of the predictive skill. In CMIP5, most decadal prediction 
systems comprise up to ten realizations of yearly initialized hindcasts and thus several of hundreds of simulations, which can hardly be downscaled by a purely dynamical downscaling (hereafter DD) with regional climate models (RCMs). Therefore, an alternative downscaling approach for the regionalization of large ensembles of decadal hindcasts is required.

The same line of thought also applies to the regionalization of long-term climate change projections, where global climate model's (GCMs) output needs to be downscaled to the regional and local scales. With this aim, several downscaling techniques have been developed and applied in recent years. They can be roughly classified as statistical, dynamical or statistical-dynamical approaches (Hewitson and Crane, 1996; Wilby and Wigley, 1997; Fuentes and Heimann, 2000; Maraun et al., 2010). In terms of the regional impact of climate change on wind energy potentials, Nolan et al. (2012) analyse possible changes in wind energy resources of Ireland with a DD approach (ECHAM5/MPI-OM1 GCM ensemble simulations and one RCM). Hueging et al. (2013) investigated regional changes in wind energy potential for Europe by considering ensemble projections from two RCMs driven by ECHAM5/MPI-OM1 simulations (A1B scenario). An empirical downscaling method has been employed by, for example, Pryor et al. (2005) to estimate the future change in wind energy, using wind observations as predictands and large-scale atmospheric fields of ECHAM4/OPYC3 as predictors. In these and other studies, the analysis focuses typically on single emission scenarios or a single GCM/RCM. In case of the DD methods, this is surely due to the very time-consuming high-resolution simulations of the RCMs. At the same time, several studies reveal that uncertainties in the future projections of synoptic variability in GCMs arise not only from different greenhouse gas forcings but also from discrepancies between individual GCMs using the same scenario that may be quite large, e.g. because of different parameterizations or uncertainties in ocean circulation changes (e.g. Ulbrich et al., 2008; Harvey et al., 2012; Woollings et al., 2012). Because of these uncertainties, a downscaling methodology for wind energy, which can easily be applied to large (multi-model) ensembles of long-term future projections, would be beneficial. A useful method for downscaling multiple GCMs is the expansion of DD applications by statistical approaches (e.g. Fuentes and Heimann, 2000). For wind applications, for example, Najac et al. (2011) have recently combined mesoscale modelling with statistical transfer functions between large-scale and local winds to infer the impact of climate change on surface winds over France.

In this study, a statistical-dynamical downscaling (SDD) approach for wind energy applications on the regional scale in Europe with special focus on Germany is proposed and evaluated. The aim of the study is to investigate in how far:

- SDD is able to simulate realistic near-surface wind distributions for recent climate conditions;
- SDD produces comparable results to the timeconsuming DD with respect to the simulation of wind energy output on different timescales;

- SDD is efficient for the application to large ensembles of both decadal hindcasts and long-term climate change projections to assess the changes of wind energy in near future and to the end of the 21 st century in multi-model ensembles.

This study is organized as follows. The methodology of SDD and the used data sets are introduced in Section 2. Results of SDD as applied to different exemplary global data sets are discussed in the following sections: Section 3 describes the evaluation of SDD based on ERA-Interim Reanalysis data, Section 4 describes the application on the Earth System Model of the Max Planck Institute (MPI-ESM) decadal hindcasts, and Section 5 describes investigations based on climate change projections with the ECHAM5 model. A short discussion concludes this paper.

\section{Methods and data}

The proposed SDD approach (following Fuentes and Heimann, 2000; Pinto et al., 2010) for the simulation of highly-resolved wind energy output consists of four crucial steps (see Figure 1). These steps will be introduced and described in detail in the following. For convenience, the stepwise application of SDD to a reanalysis data set is presented. The application to other data sets, such as decadal hindcasts, is quite similar and will be described later in this section (see below).

Step 1: In the first step of SDD approach, a weather typing approach is used to characterize the large-scale circulation of each day (see Figure 1). With this aim, the circulation weather type (CWT) approach from Jones et al. (1993) is considered. This approach follows the manual Lamb weather types (Lamb, 1972; Jenkinson and Collinson, 1977) and has been widely used in many applications (e.g. Jones et al., 2012). Daily mean sea level pressure (MSLP) fields of the ERA-Interim reanalysis project (Dee et al., 2011) are used as input data. This data set comprises the period 1979-2010 and is interpolated on a $2.5^{\circ}$ grid for the computation of the CWTs. By regarding instantaneous MSLP values at 16 points around the central point at $10^{\circ} \mathrm{E}, 50^{\circ} \mathrm{N}$ (near Frankfurt, Germany; cf. Figure 2), the near-surface atmospheric flow for each day is determined and assigned to one of the ten basic CWTs: northeast, NE; east, E; southeast; SE; south, $\mathrm{S}$; southwest, SW; west, W; northwest, NW; north, N; cyclonic, $\mathrm{C}$; anti-cyclonic, $\mathrm{A}$. In addition, the mixed type anti-cyclonic/west $\mathrm{A} / \mathrm{W}$ is considered as its frequency is comparable to the values of some of the basic CWTs and should, therefore, not be neglected. For wind energy, a further crucial factor is the strength of the geostrophic flow. Therefore, aside from the direction of flow, a $f$-parameter representing the gradient of the instantaneous MSLP field at the central point is calculated. Depending on the CWT, the $f$-parameter ranges from ca. $45 \mathrm{hPa}$ per 

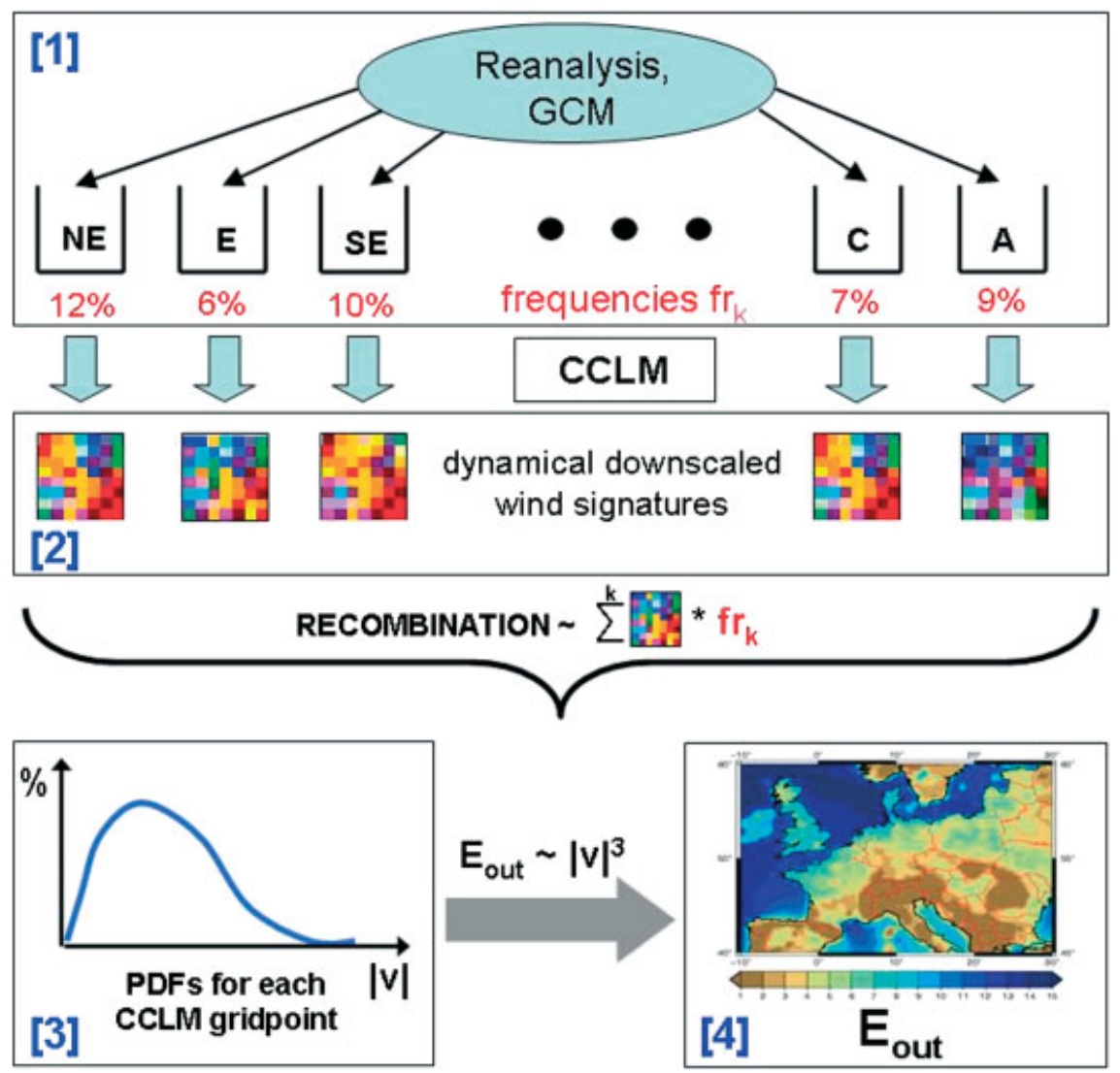

Figure 1. Schematic illustration of the SDD with its four crucial steps: 1 - large-scale weather type analysis; 2 - DD of representative days for each weather class; 3 - recombination of simulated wind signatures for the representatives to PDFs of 10-m wind speed for each CCLM grid point; 4 - determination of spatial distributions of regional $E_{\text {out }}$ by applying wind turbine characteristics to the PDFs. The single steps are described in detail in Section 2.

$1000 \mathrm{~km}$ (strong MSLP gradient) to values below $5 \mathrm{hPa}$ per $1000 \mathrm{~km}$ (slack MSLP gradient). To capture the full spectrum of potential wind velocities within a CWT, each of the $11 \mathrm{CWTs}$ is subdivided into classes of $f$-parameters with $5 \mathrm{hPa}$ per $1000 \mathrm{~km}$ intervals $(0-5$ to $40-45 \mathrm{hPa}$ per $1000 \mathrm{~km})$. Altogether, a total of 77 classes have been identified (see Table 1). As an example, Figure 2 shows climatological MSLP fields for class W, with $f$-parameter 0-5 versus $35-40 \mathrm{hPa}$ per $1000 \mathrm{~km}$, and for class $\mathrm{C}$, with $f$-parameter $0-5$ versus $20-25 \mathrm{hPa}$ per $1000 \mathrm{~km}$. As expected, classes with high $f$-parameters (Figure 2(b) and (d)) show a much stronger MSLP gradient around the central point and thus higher geostrophic wind speeds than classes with low $f$-parameters (Figure 2(a) and (c)).

Step 2: To obtain highly resolved wind signatures of the different classes, in the second step of SDD, representative days for each of the 77 classes are simulated with the regional COSMO model of the German Weather Forecast Service Deutscher Wetterdienst (DWD) (http://www.cosmo-model.org) in its CLimate Mode (version 4.8, hereafter CCLM). CCLM is a three-dimensional, non-hydrostatic atmospheric circulation model with generalized terrain-following height level on a rotated coordinate system (Rockel et al., 2008). CCLM simulations are performed with a horizontal resolution of $0.22^{\circ} \times 0.22^{\circ}$, using ERA-Interim data as initial and boundary conditions.
The model domain is consistent with the domain used in the EURO-CORDEX project (Giorgi et al., 2006), comprising the European-East Atlantic sector with 226 grid points in south-north and 232 grid points in west-east direction. It roughly ranges from $20^{\circ} \mathrm{N}$ to $70^{\circ} \mathrm{N}$ and from $30^{\circ} \mathrm{W}$ to $50^{\circ} \mathrm{E}$.

For each of the 77 classes, ten representative days were selected (see Appendix S1), if available, and simulated with CCLM. If a class occurs on $<10$ days within the ERA-Interim period 1979-2010, the full set of days is used as representatives. A total of 669 representative days have been simulated. The choice of the representative days within a class is random, but we have selected representatives from all four seasons if possible. As this is a quite large number of selected days, it can be assumed that the full spectrum of potential representatives is largely covered by this method and thus the variability of the target parameter (wind) both for each weather class and climatology.

Step 3: In the third step, CCLM-simulated hourly $10-\mathrm{m}$ winds of the representative days are recombined to wind velocity distributions [probability density functions (PDFs)] for the full ERA-Interim period 1979-2010. The PDFs are determined for each CCLM grid point, separately: for a given wind velocity $\left(0.1 \mathrm{~m} \mathrm{~s}^{-1}\right.$ velocity ranges), the respective occurrence is calculated as sum of the contributions of all classes weighted by 
(a)

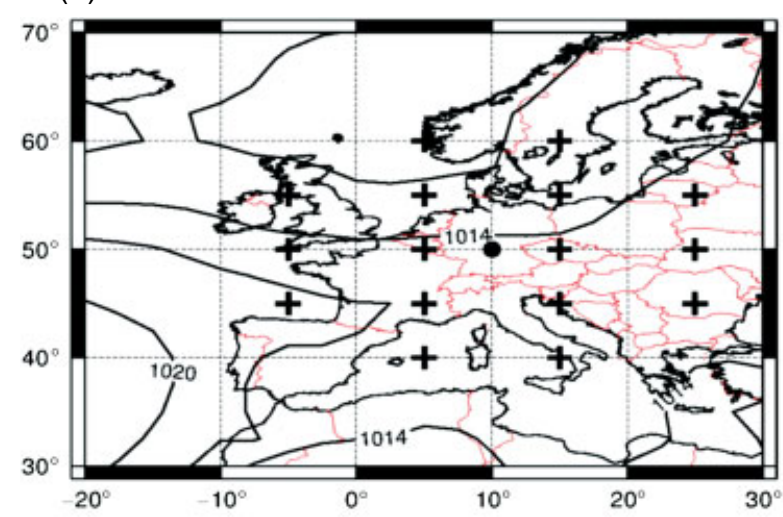

(c)

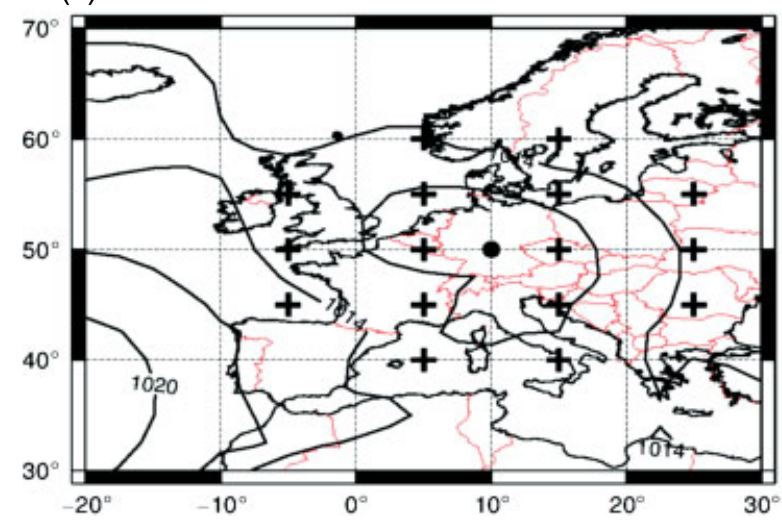

(b)

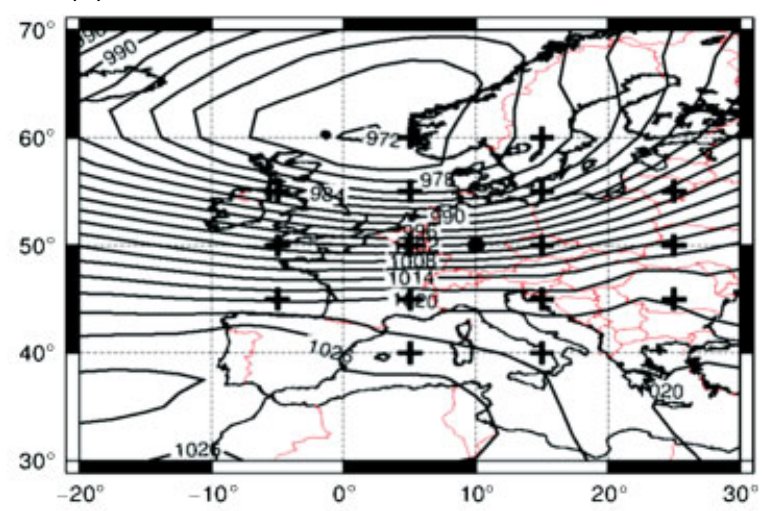

(d)

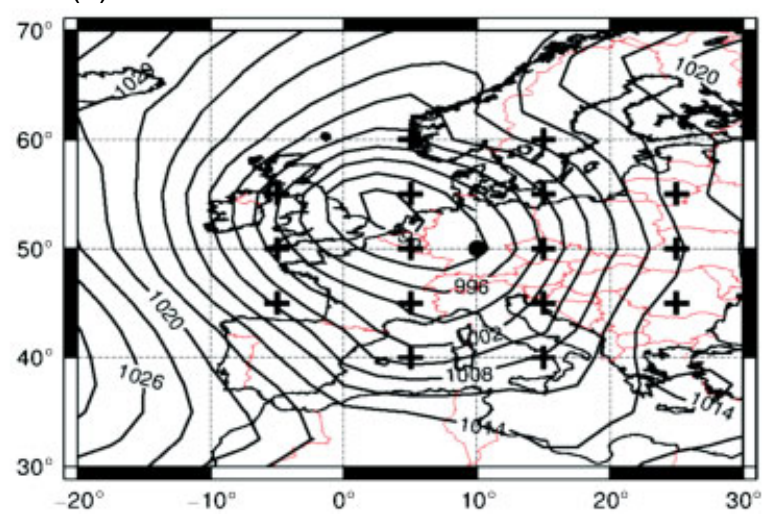

Figure 2. Climatological means of exemplary CWT classes as obtained from MSLP fields of ERA-Interim. (a) CWT W with $f$-parameter between 0 and $5 \mathrm{hPa}$ per $1000 \mathrm{~km}$. (b) CWT W with $f$-parameter between 35 and $40 \mathrm{hPa}$ per $1000 \mathrm{~km}$. (c) CWT C with $f$-parameter between 0 and $5 \mathrm{hPa}$ per $1000 \mathrm{~km}$. (d) CWT C with $f$-parameter between 20 and $25 \mathrm{hPa}$ per $1000 \mathrm{~km}$. The black point represents the central point for the CWT analysis, the black crosses the surrounding ERA-Interim grid points used for the computation of the CWTs. For more details, see text.

Table 1. Relative frequency, range of $f$-parameter (in hPa per $1000 \mathrm{~km}$ ), and number of classes of each CWT. The last row shows the total of identified CWT classes.

\begin{tabular}{lccc}
\hline CWT & Frequencies $(\%)$ & $f$-Range & No. of classes \\
\hline NE & 4.01 & $0-30$ & 6 \\
E & 4.34 & $0-30$ & 6 \\
SE & 4.93 & $0-35$ & 7 \\
S & 5.36 & $0-35$ & 7 \\
SW & 9.86 & $0-45$ & 9 \\
W & 9.58 & $0-45$ & 9 \\
NW & 8.17 & $0-45$ & 9 \\
N & 5.29 & $0-35$ & 7 \\
C & 12.02 & $0-25$ & 5 \\
A & 32.16 & $0-25$ & 5 \\
A/W & 4.30 & $0-35$ & 7 \\
Total no. of classes & & 77 \\
\hline
\end{tabular}

the climatological class frequency and the number of simulated representatives.

Step 4: The climatological 10-m wind speed PDFs form the basis for the determination of mean wind energy output $\left(E_{\text {out }}\right)$ following Hueging et al. (2013). First, 10-m wind velocities are extrapolated to a height of $80 \mathrm{~m}$, which is assumed to be the average hub height of onshore wind turbines (EEA, 2009). For the extrapolation, the power law is used:

$$
\frac{v(z)}{v\left(z_{\mathrm{r}}\right)}=\left(\frac{z}{z_{\mathrm{r}}}\right)^{\alpha},
$$

with $v(z)$ and $v\left(z_{\mathrm{r}}\right)$ being the wind velocities in $80 \mathrm{~m}(z)$ and $10 \mathrm{~m}\left(z_{\mathrm{r}}\right)$, respectively. The parameter $\alpha$ is the power law exponent, which is set to 0.2 for onshore areas and to 0.14 for offshore sites (IEC, 2005a, 2005b). Wind velocities of $80 \mathrm{~m}$ are then used to compute $E_{\text {out }}$, using wind turbine characteristics of an idealized 2.5 MW wind turbine from General Electric (2010):

- No energy output is produced below 80-m wind velocities of $3.5 \mathrm{~m} \mathrm{~s}^{-1}$ (cut-in velocity) and for velocities higher than $25 \mathrm{~m} \mathrm{~s}^{-1}$ (cut-out velocity).

- Between wind velocities of $3.5 \mathrm{~m} \mathrm{~s}^{-1}$ (cut-in velocity) and $12.5 \mathrm{~m} \mathrm{~s}^{-1}$ (rated velocity), $E_{\text {out }}$ can be determined as follows:

$$
E_{\text {out }}=c_{\mathrm{p}} \frac{1}{2} \rho \pi R^{2} v_{80}^{3}
$$

where $c_{\mathrm{p}}$ is the power coefficient $(0.35), \rho$ is the air density (constant value of $1.225 \mathrm{~kg} \mathrm{~m}^{-3}$ ), $R$ is the rotor radius of 
the idealized wind turbine $(50 \mathrm{~m})$, and $v_{80}$ is the $80-\mathrm{m}$ wind velocity.

- Between wind velocities of $12.5 \mathrm{~m} \mathrm{~s}^{-1}$ (rated velocity) and $25 \mathrm{~m} \mathrm{~s}^{-1}$ (cut-out velocity), a constant energy output of $2.5 \mathrm{MW}$ is assumed.

To obtain spatial distributions of mean annual wind energy output for the period 1979-2010, for each CCLM grid point, computed $E_{\text {out }}$ is integrated over all wind velocity ranges of the gridded PDFs, using the respective climatological velocity frequencies as weighting factors.

For the application of SDD method to shorter time periods or to other data sets, only the weather typing analysis (step 1) has to be adapted to these new data sets. If, for example, $E_{\text {out }}$ is to be simulated on annual timescales, the CWT analysis is carried out for single years. In steps 2-4, the resulting weather class frequencies (e.g. for single years) are then used in the same manner as for ERA-Interim climatology to obtain 10-m wind speed PDFs and finally spatial distributions of regional $E_{\text {out }}$, using the same simulated representative days as for the full ERA-Interim period. This assumes that the selected days are also representative for the weather classes in other data sets, only the frequencies of the classes will change (e.g. in future projections).

In this study, the SDD approach is applied to three different data sets. For evaluation purposes, the SDD approach is applied to ERA-Interim as described above. To calculate adequate $E_{\text {out }}$ values, realistic simulations of $10-\mathrm{m}$ wind speed PDFs are required (see step 3 ). In this respect, SDD-simulated PDFs are compared to PDFs as derived from observations. Hourly $10-\mathrm{m}$ wind velocities from stations of the German Weather Forecast Service (DWD) are used. We have only regarded stations with a height below $800 \mathrm{~m}$ asl, where measurements cover more than $98 \%$ of the period 1979-2010. Furthermore, SDD-simulated $E_{\text {out }}$ is compared to $E_{\text {out }}$ simulations of a purely DD method. The DD run is simulated with CCLM, using continuous ERA-Interim data from 1979 to 2010 as boundary conditions (hereafter $\mathrm{DD}_{\text {era }}$ ). For $\mathrm{DD}_{\text {era }}, E_{\text {out }}$ is computed from hourly 10-m wind velocity output and then summed up for certain periods, using the same turbine characteristics as for SDD (see Equations 1 and 2). Aside from climatological means, results of SDD for selected time periods are compared to $\mathrm{DD}_{\text {era }}$ results.

In terms of applications, the SDD approach is applied to the decadal prediction system of the coupled MPI-ESM (Mueller et al., 2012). The latest experiment version is used (MPI-ESM Baseline1), where initial conditions for decadal hindcasts and predictions are taken from assimilation runs forced by sea surface temperature and salinity anomalies of the operational ECMWF ocean reanalysis system (ORAs4; Balmaseda et al., 2013). This experiment comprises ten realizations of yearly initialized decadal hindcasts and predictions from 1960 to 2011 (hereafter dec1960 to dec2011; altogether $52 \times 10=520$ realizations), each of them covering a period of 10 years. SDD results are compared to outcomes as obtained by the DD method. Four DD runs are simulated with CCLM, using atmospheric fields of four selected decadal hindcasts as boundary conditions: first realization of dec1980 (initialized at 01.01.1981; hereafter $\mathrm{DD}_{1980}$ ), first realization of dec2000 (initialized at 01.01.2001; hereafter $\mathrm{DD}_{2000 \_1}$ ), and the first and tenth realization of dec1990 (initialized at 01.01.1991, respectively; hereafter $\mathrm{DD}_{1990 \_1}$ and $\mathrm{DD}_{1990 \_10}$ ).

To demonstrate that SDD is appropriate for the application to ensembles of long-term climate change projections, we employ the method also to simulations with the GCM ECHAM5/MPI-OM of the Max-Planck-Institute Hamburg (hereafter ECHAM5; Jungclaus et al., 2006; Roeckner et al., 2006). SDD is applied to an ensemble for recent climate conditions (20C scenario, 1961-2000) and to the three scenarios B1, A1B, and A2 (2061-2100, respectively) of the Special Report on Emission Scenarios (SRES; Nakicenovic and Swart, 2000) to estimate regional changes of wind energy by the end of the $21 \mathrm{st}$ century. As the projected changes for pressure gradients and winds under future climate conditions for Europe on the regional scale are comparatively small (e.g. Hueging et al., 2013), it can be assumed that primarily only the frequencies of the weather classes will change in future climate, while the wind characteristics within each class will remain largely unchanged. Therefore, the selected representatives are considered as suitable also for the climate conditions during the second half of the 21 st century. The $\mathrm{CO}_{2}$ concentration increases from $367 \mathrm{ppm}$ in the year 2000 to 540,703 , and $836 \mathrm{ppm}$ by the year 2100 for B1, $\mathrm{A} 1 \mathrm{~B}$, and A2, respectively. For the A1B scenario, results of SDD are compared to Hueging et al. (2013), who have employed two different RCMs (inter alia the CCLM) to simulate regional changes in wind energy potential over Europe using the first two realizations of ECHAM5 20C and $\mathrm{A} 1 \mathrm{~B}$ as boundary conditions.

\section{Evaluation and application to ERA-Interim}

In this section, results of the single steps of the SDD application to ERA-Interim are presented and evaluated against observations and $\mathrm{DD}_{\text {era }}$. Figure 3 shows the climatological frequencies of the 77 classes for the period 1979-2010 as obtained from the weather typing approach (step 1). The most dominating CWTs are A, C, and the westerly types (SW, W, NW). While for CWT A, the observed $f$-parameter range is mainly restricted to low values $(0-5$ and $5-10 \mathrm{hPa}$ per $1000 \mathrm{~km})$, frequencies of the CWTs SW, W, and NW are highest for $f$-parameter ranges of 5-10 to $20-25 \mathrm{hPa}$ per $1000 \mathrm{~km}$. These results reflect that anti-cyclonic conditions are generally related to weak MSLP gradients, and that westerly flows are predominantly connected with stronger near-surface winds. Lowest frequencies are found for the easterly CWTs (SE, E, NE).

As described in Section 2, the frequencies of the 77 weather classes are used for the recombination of 


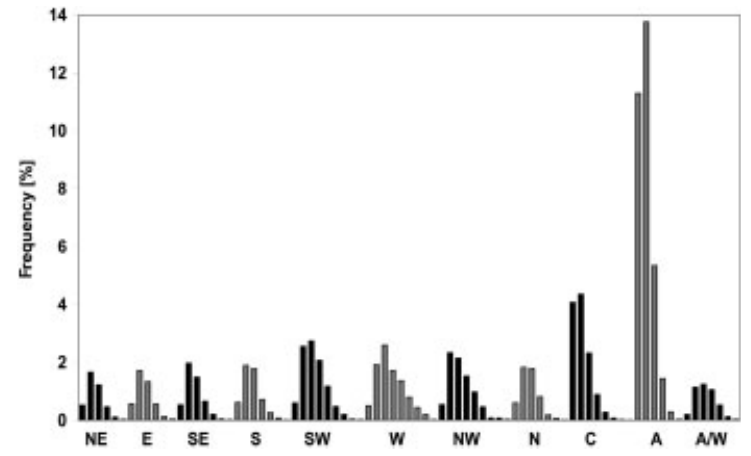

Figure 3. Climatological frequencies of all weather classes for ERA-Interim (1979-2010). For each CWT, weather classes are shown for ascending $f$-parameter $(5 \mathrm{hPa}$ per $1000 \mathrm{~km}$ intervals) from left to right $(0-5,5-10,10-15 \mathrm{hPa}$ per $1000 \mathrm{~km}$, etc.). For better indication, the CWTs are separated by black and grey colouring.

simulated representative days (step 2) to downscaled PDFs of 10-m wind velocities per COSMO-CLM grid point (step 3). According to the wind turbine characteristics used in this study (see Equations 2), the majority of $E_{\text {out }}$ is produced by upper wind percentiles. Figure 4 exemplary shows the 75 th and 90th percentiles for the period 1979-2010 as derived from SDD and DD $_{\text {era }}$. Differences between SDD- and $\mathrm{DD}_{\text {era }}$-simulated percentiles are quite small for the entire European sector (see Figure $4(\mathrm{a})-(\mathrm{d}))$. Both SDD and $\mathrm{DD}_{\text {era }}$ reveal highest percentiles over sea surfaces and at the northern coasts, and smallest percentiles over the Alps and in southeast Europe.

Compared to observations, the 75th and 90th percentiles are overestimated by SDD for some stations in Mid-Germany, whereas for most stations in western and southern Germany as well as in the coastal area, SDD-simulated percentiles agree well to observations (see Figure 5). In general, the north-south gradient observed for Germany, with strongest percentiles at the coasts and lowest percentiles near the Alps, is matched well by the SDD approach.

For eight exemplary stations (for location of the stations, see Figure 5(a)), full PDFs are compared to PDFs for the respective nearest CCLM grid point as derived by SDD (1979-2010, see Figure 6). Please note that frequencies for the six stations in former West Germany are shown in $0.5 \mathrm{~m} \mathrm{~s}^{-1}$ intervals, whereas frequencies for Schwerin (SW) and Leipzig (LE) are given in $1 \mathrm{~m} \mathrm{~s}^{-1}$
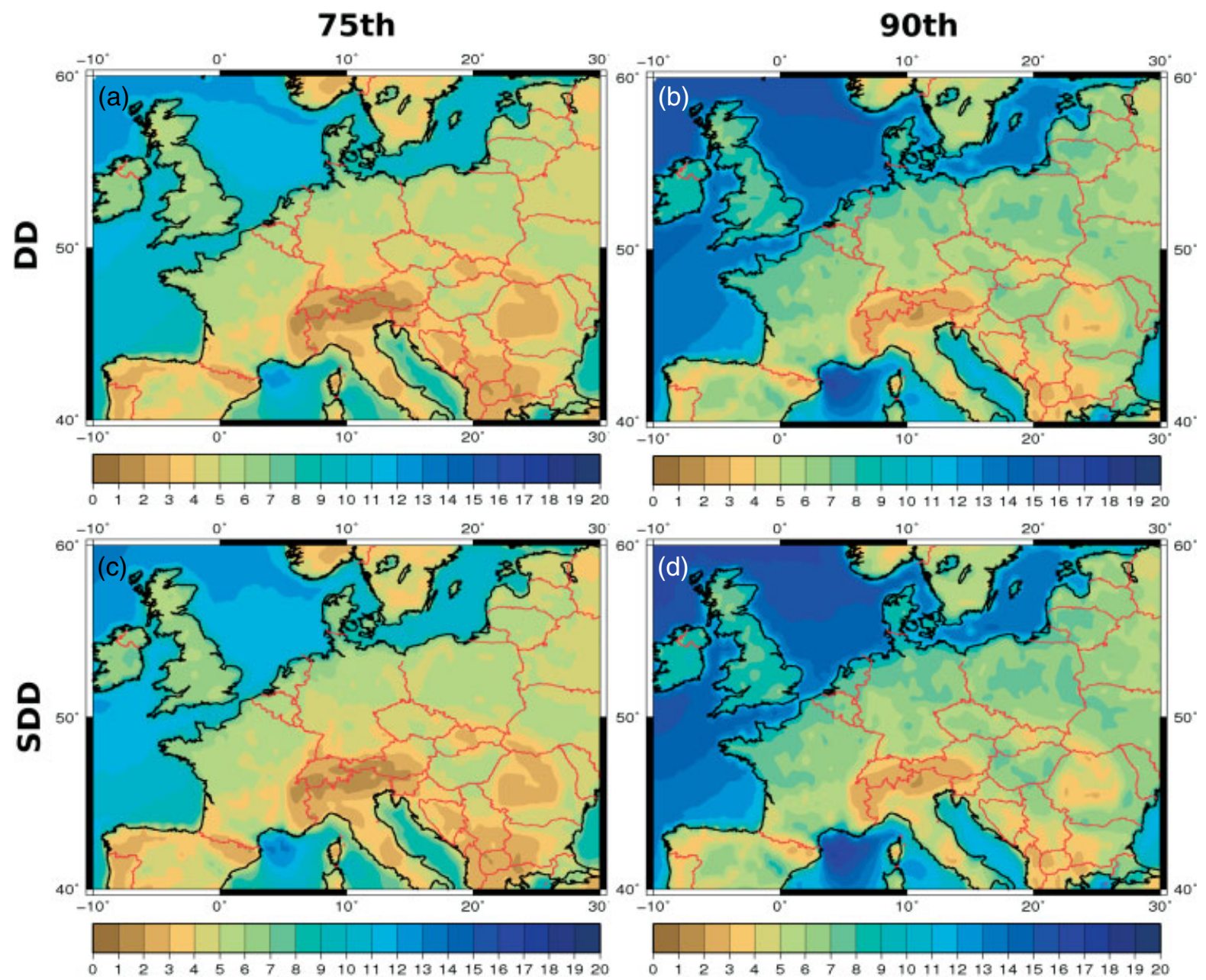

Figure 4. 75th (left column) and 90th (right column) percentiles in $\mathrm{m} \mathrm{s}^{-1}$ of the 10-m wind velocity for the period 1979-2010. Upper row, DD; lower row, SDD 

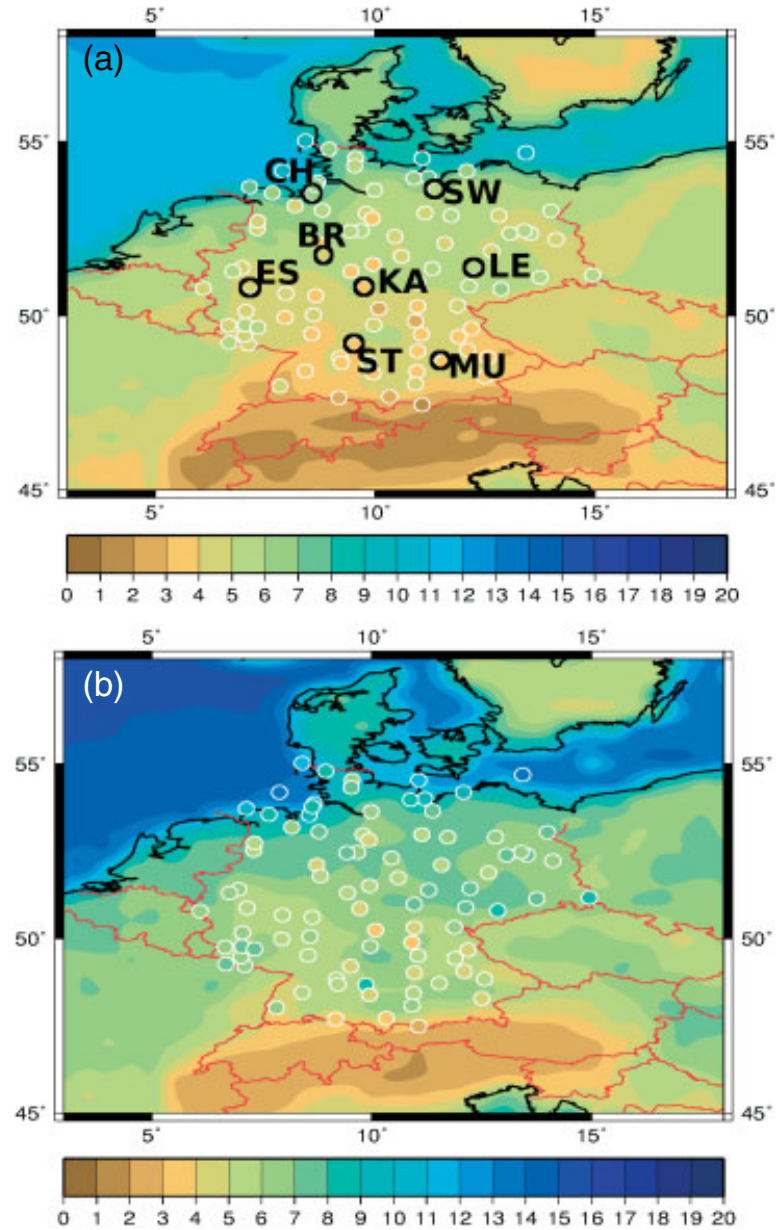

Figure 5. (a) 75th and (b) 90th percentiles in $\mathrm{m} \mathrm{s}^{-1}$ of the 10-m wind velocity for the period $1979-2010$ as obtained by SDD (shaded) and observations (small circles). Note that (a) shows a zoom of Figure 4(c), and (b) shows a zoom of Figure 4(d). The black circles in (a) mark the locations of the stations shown in Figure 6: CH, Cuxhaven; BR, Bremen; SW, Schwerin; ES, Essen; KA, Kassel; LE, Leipzig; ST, Stuttgart; MU, Munich.

intervals (due to different measurement accuracy in former east Germany before 1990). Discrepancies between SDD-simulated and observed PDFs are largest for the coastal and near-coastal stations Cuxhaven $(\mathrm{CH})$, Bremen (BR), and Schwerin (SW), while PDFs are simulated quite realistic for the non-coastal stations. However, the general observed wind distributions are captured well by the SDD approach, with highest wind speeds occurring in the North and frequent low wind velocities in southern Germany. The same PDFs have been derived from $\mathrm{DD}_{\text {era }}$ simulations. These PDFs are for most stations similar to the PDFs as obtained by the SDD approach. Only for few stations, results from $\mathrm{DD}_{\text {era }}$ show a slightly higher agreement to observations than SDD-simulated PDFs (e.g. Essen and Munich).

The gridded PDFs of the 10-m wind velocity for the period 1979-2010 are used to compute climatological annual means of $E_{\text {out }}$ per CCLM model grid point (step 4). The spatial pattern of $E_{\text {out }}$ as obtained by the SDD approach is realistic and quite similar to $\mathrm{DD}_{\text {era }}$-simulated
$E_{\text {out }}$, with highest values over ocean surfaces and rather small output over mountainous areas and southeast Europe (see Figure 7(a) and (b)). Only the magnitudes between both downscaling methods slightly differ. For most regions, $\mathrm{SDD}$ simulates higher $E_{\text {out }}$ values than $\mathrm{DD}_{\text {era }}$, but deviations are quite small compared with absolute magnitudes (see Figure 7(c)). The main positive bias of SDD compared to $\mathrm{DD}_{\text {era }}$ results from a slight overestimation of the frequencies of high wind speeds by SDD, as can be seen for most of the eight stations in Germany presented in Figure 6. Although the differences between the PDFs of SDD and $\mathrm{DD}_{\text {era }}$ are actually very small, they still lead to a slight but visible overestimation of wind energy output by SDD, as $E_{\text {out }}$ is proportional to $v^{3}$.

For the application to decadal predictions, SDD should be able to simulate suitable $E_{\text {out }}$ anomalies on timescales from several years down to single years. This is first tested for ERA-Interim by comparing annual time series of $E_{\text {out }}$ anomalies as simulated by SDD to time series derived from $\mathrm{DD}_{\mathrm{era}}$. Figure 8 shows such a comparison for six exemplary sub-regions in central Europe (for location of the sub-regions, see Figure 7(a)). For Belgium, central Germany, northern Germany, and Poland, the time series of both methods are quite similar. Despite a slight underestimation of the general variability by SDD compared to $\mathrm{DD}_{\text {era }}$, the year-to-year variation is captured well. Larger discrepancies between the two methods of up to $800 \mathrm{MWh}$ year $^{-1}$ can be seen for a sub-region in northern France, where the annual variability is clearly underestimated by SDD. Nevertheless, for most years, the anomalies of both methods have the same sign. Differences between SDD and $\mathrm{DD}_{\text {era }}$ are largest for a sub-region in the North Sea. Comparisons of time series of 5-year running means and for other sub-regions also reveal a good accordance between SDD and $\mathrm{DD}_{\text {era }}$ for land surfaces in central Europe and a lower agreement over ocean surfaces (not shown). Even over the Baltic States, SDD-simulated time series of $E_{\text {out }}$ are similar to $\mathrm{DD}_{\text {era }}$. An overview of the regions with a high agreement between SDD and $D_{\text {era }}$ is given by Figure 9(a), which shows the correlation between annual $E_{\text {out }}$ time series of both downscaling methods for all CCLM grid points. Very high correlations of more than 0.8 can be seen for Germany, Benelux, and Poland. Significant positive correlations of up to 0.8 are found for Great Britain, Czech Republic, and parts of the Baltic States, while correlation is low for southern Europe and the North Sea. This is due to the used weather typing approach, which is only representative for the large scale flow at the surrounding of the central point (in this case Germany and nearby areas) but not for areas far away from it (e.g. Italy). A physical explanation for the comparable low correlation over the North Sea is the high roughness length variability over sea surfaces due to varying heights of the water waves, which cannot be fully captured by SDD on timescales down to single years (unlike DD), as the same simulated representatives are used every time (see Section 2).

Figure 9(b) shows the RMSE of the SDD time series relative to the time series as obtained by $\mathrm{DD}_{\text {era }}$. To take into 

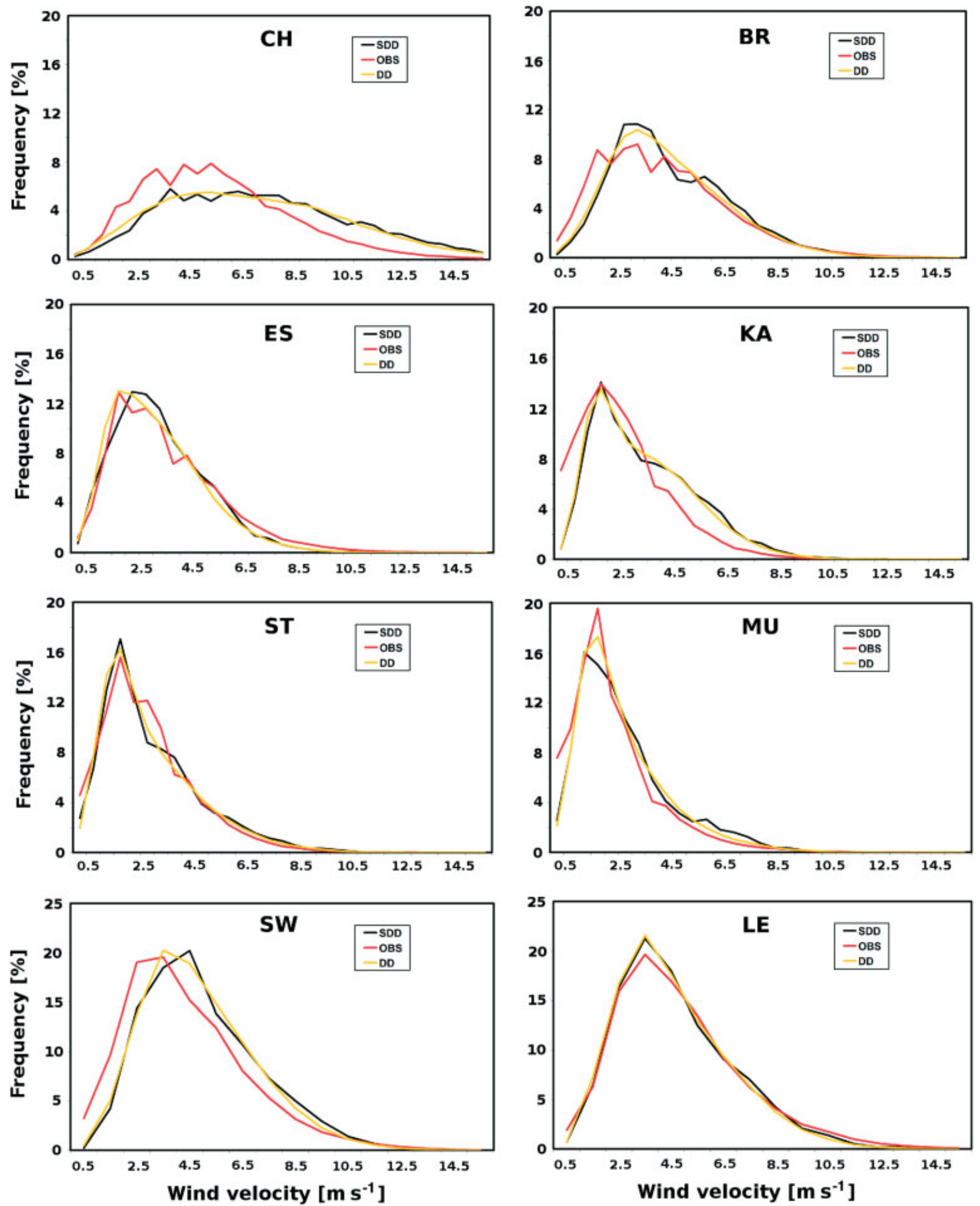

Figure 6. PDFs of the 10-m wind velocity for the period 1979-2010 at eight exemplary stations and at the corresponding CCLM grid points. Black line, SDD; dark grey line, observations; bright grey line, DD. Locations of the stations are shown in Figure 5(a). Please note that frequencies for the upper six stations are shown in $0.5 \mathrm{~m} \mathrm{~s}^{-1}$ intervals, and for the lower two stations in $1 \mathrm{~m} \mathrm{~s}^{-1}$ intervals.

account that the RMSE is inherently small over regions with low $E_{\text {out }}$ and thus low variability (like e.g. the Alps) and vice versa, the RMSE is normed by the standard deviation of $\mathrm{DD}_{\text {era }}$. Over central Europe, regions with small RMSE correspond well to regions with a high correlation between both time series (cf. Figure 9(a)). This implies that for these areas, SDD is not only able to capture the year-to-year variation in wind energy output (Figure 9(a)), but also simulates magnitudes of $E_{\text {out }}$, which are similar to that of $\mathrm{DD}_{\text {era }}$ (Figure 9(b)). 

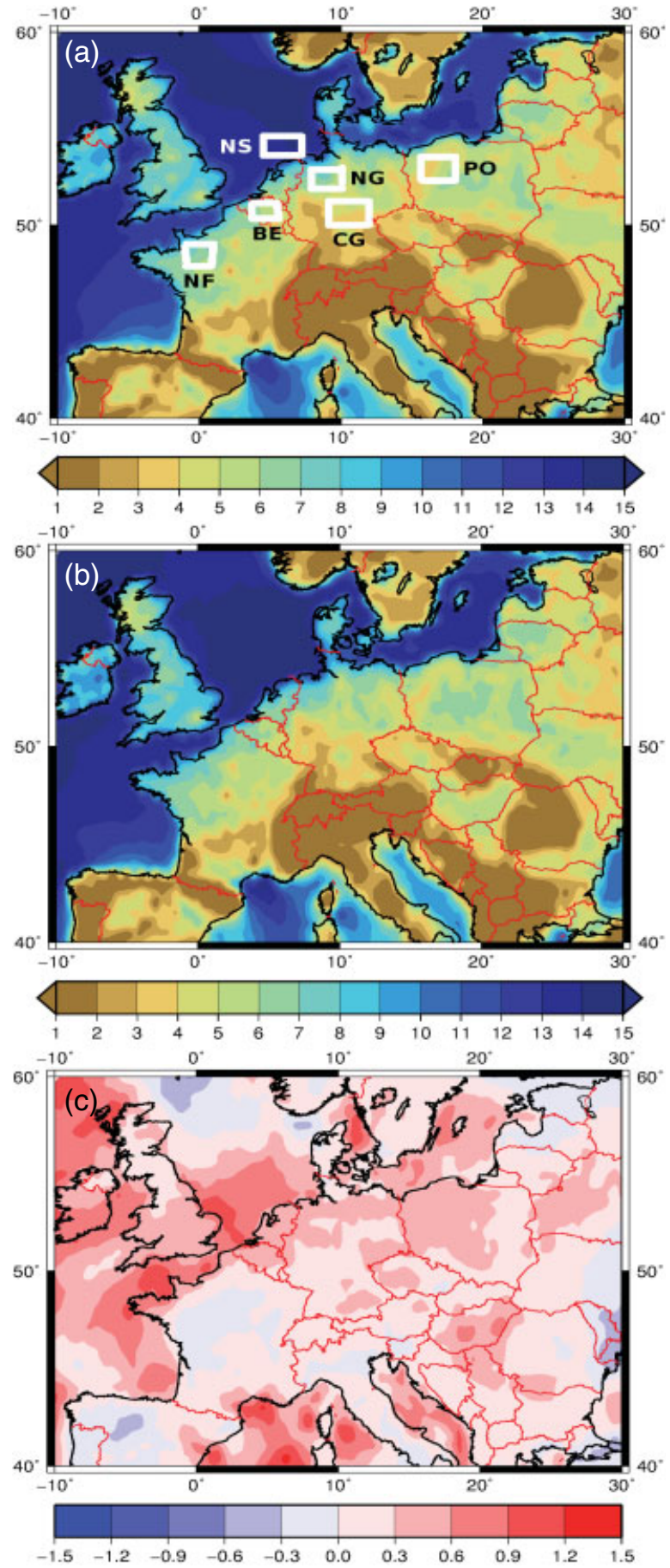

Figure 7. (a) Annual mean of $E_{\text {out }}$ in $10^{3} \mathrm{MWh}$ year $^{-1}$ for ERA-Interim (1979-2010) as obtained by $\mathrm{DD}_{\text {era }}$. (b) Annual mean of $E_{\text {out }}$ in $10^{3}$ MWh year $^{-1}$ for ERA-Interim (1979-2010) as obtained by SDD. (c) Difference between $E_{\text {out }}$ from SDD and from $\mathrm{DD}_{\text {era }}$ in $10^{3} \mathrm{MWh}$ year $^{-1}$. The boxes in (a) represent sub-regions for the computation of $E_{\text {out }}$ time series as shown in Figures 8 and 10.

\section{Application to decadal hindcasts and predictions}

The objective of this subsection is to investigate whether SDD is appropriate for the application to the full ensemble of the decadal prediction system of the MPI-ESM (520 decadal hindcasts and predictions with a length of 10 years). It should be kept in mind that a detailed evaluation of a potential predictive skill of the MPI-ESM on the regional scale is still ongoing and is not the purpose of this study. This will be analysed in a separate study.

Like for ERA-Interim, results of SDD application to MPI-ESM are compared to the outcomes of DD. Here, four selected decadal hindcasts are regarded. Again, simulated annual time series of $E_{\text {out }}$ anomalies of both methods are compared. Figure 10 exemplary shows the annual $E_{\text {out }}$ anomalies of both methods for the first realization of dec1980 (1 January 1981 to 31 December 1990). Despite a slightly lower variability of SDD, time series of both methods are quite similar. The accordance between SDD and $\mathrm{DD}_{1980 \_1}$ is highest for Belgium (BE), sub-regions in Germany, and Poland, while discrepancies are stronger for the sub-region in northern France and over the North Sea. Similar results are found for the first and tenth realization of dec1990 and the first realization of dec2000 (not shown). These outcomes are confirmed when regarding the correlation per grid point between the simulated time series of SDD and DD methods (Figure 11). For all four analysed hindcasts, correlations between SDD and DD are highest for grid points over Germany, for which the 77 weather classes were defined (see Section 2). High and, in most cases, significant correlations are also found for Poland and the Benelux. Also for the coastal areas of these countries, where high energy output is produced, SDD simulations agree well to the DD method. Compared to ERA-Interim (cf. Figure 9(a)) correlation between SDD and DD is lower at grid points over the Baltic States. Like for ERA-Interim, we have also computed the RMSE of the SDD time series relative to the time series as obtained by DD (not shown). Again, regions with small RMSE correspond well to regions with high correlations (cf. Figure 11), which means that the magnitudes of $E_{\text {out }}$ as simulated by SDD are similar to those of DD for these areas (particularly Germany). To summarize, these results reveal that for onshore areas in central Europe, SDD is an appropriate alternative to time-consuming DD and can therefore be used as an applicable tool to analyse the full ensemble of the decadal prediction system of the MPI-ESM. An example for a potential application of SDD to determine a predictive skill of the MPI-ESM is given in Figure 12. For each realization of all yearly initialized decadal hindcasts and predictions, PDFs of the 10-m wind velocity for years 1-4 after initialisation are determined to generate 4-year running mean time series of $E_{\text {out }}$. Time series of the ensemble mean $E_{\text {out }}$ as well as the standard deviation (SD) between the ten realisations for the sub-region in central Germany $(\mathrm{CG})$ are shown in Figure 12(a). For comparison, the corresponding 4-year running mean time series as simulated by $\mathrm{DD}_{\text {era }}$ is presented. Not surprisingly, the ensemble mean time series of the MPI-ESM show a lower variability than time series from $\mathrm{DD}_{\text {era }}$. At the same time, the spread between the different realisations is quite large, revealing that the uncertainty arising from different initialisations is very high in the MPI-ESM decadal prediction system. The correlations between the 4-year running mean time series of $\mathrm{DD}_{\text {era }}$ and 

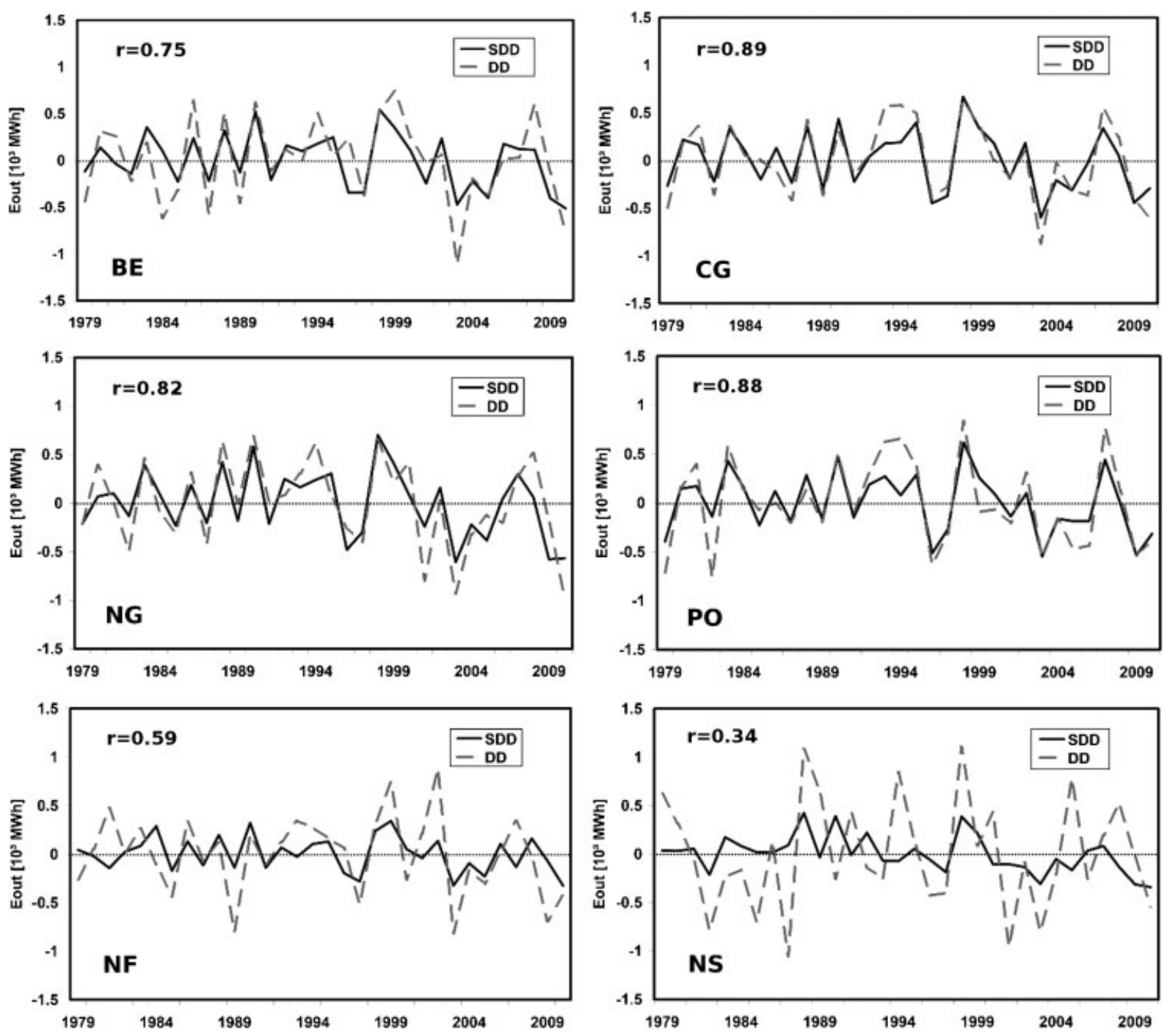

Figure 8. Time series of annual $E_{\text {out }}$ anomalies in $10^{3}$ MWh for the ERA-Interim period 1979-2010 as obtained by SDD (black solid line) and by $\mathrm{DD}_{\text {era }}$ (grey dashed line) for sub-regions in Belgium (BE), central Germany (CG), northern Germany (NG), Poland (PO), northern France (NF), and the North Sea (NS). For location of the sub-regions, see Figure 7(a). The correlations between SDD and DD time series are given in the upper left corner of each panel.

of the MPI-ESM ensemble mean for years 1-4 after initialisation are rather low or in some cases even negative for most grid points over central Europe (see Figure 12(b)). For countries in central Europe, only over The Netherlands and for a small region in Czech Republic, a significant positive correlation is found. These preliminary results suggest that with respect to wind energy on the regional scale, the predictive skill of the MPI-ESM decadal prediction system for short lead times is rather small, but a much deeper analysis is required to quantify the forecast skill.

\section{Application to climate change projections}

Finally, SDD is applied to different scenarios from the ECHAM5 model. The weather typing approach is applied to large-scale daily MSLP fields of the different ECHAM5 scenarios to obtain climatological PDFs of the 10-m wind velocity for the recent climate (20C, 1961-2000) and for the second half of the 21 st century (A1B, B1, and A2 scenarios; 2061-2100, respectively). Then, the differences between the resulting $E_{\text {out }}$ climatologies of the greenhouse gas scenarios and the $20 \mathrm{C}$ scenario are computed to determine climate change signals for wind energy (2061-2100 minus 1961-2000). For the A1B scenario, results are compared to Hueging et al. (2013), who used DD methods for their analysis. For consistency, ensemble means of the first and second realization of the scenarios are regarded.

The climatological regional $E_{\text {out }}$ patterns for the ECHAM5 20C scenario (1961-2000) as obtained by SDD are comparable to the results of Hueging et al. (2013, cf. their figure 1(e)), with highest values over ocean surfaces and near the coasts and low energy output for southeast Europe (not shown).

The regional changes of $E_{\text {out }}$ for 2061-2100 in the three SRES are shown in Figure 13. For the A1B scenario, annual changes as simulated by SDD (Figure 13(a)) are similar to the changes detected by Hueging et al. (2013, see 

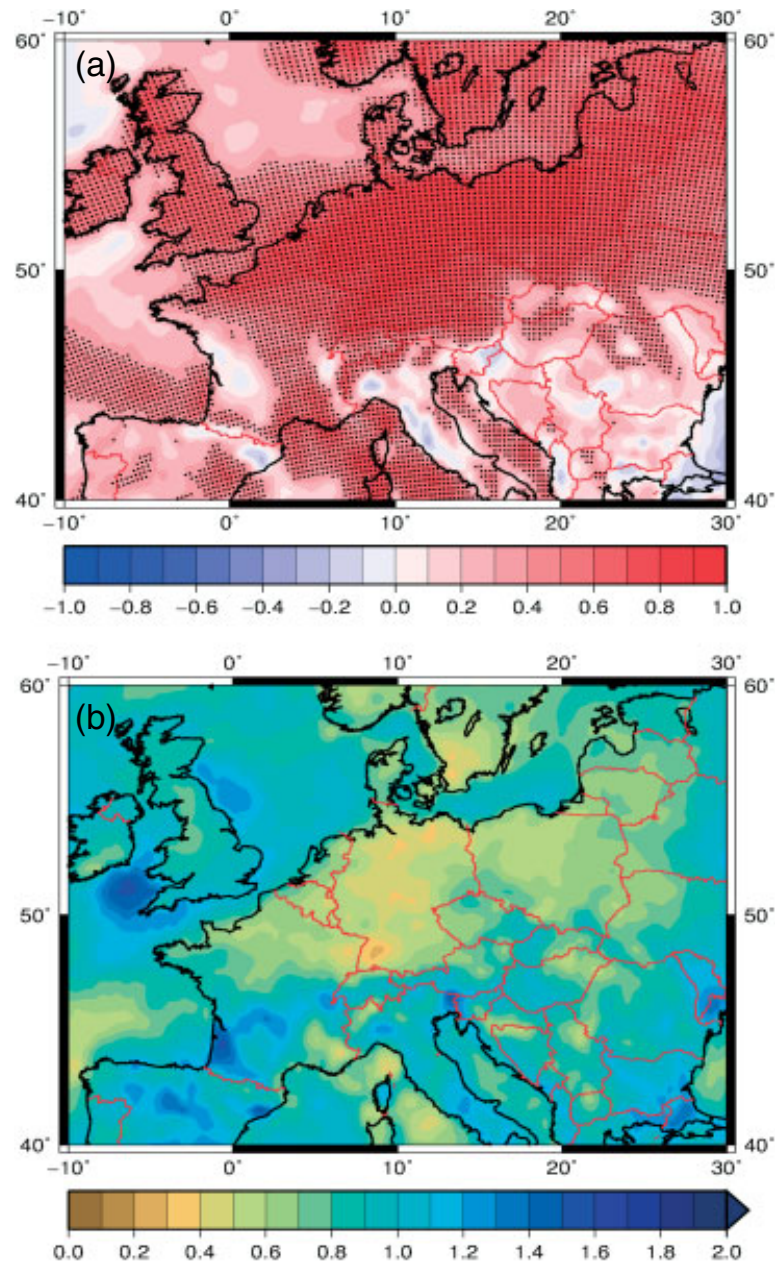

Figure 9. (a) Correlation between annual $E_{\text {out }}$ time series of SDD and $\mathrm{DD}_{\text {era }}$ per CCLM grid point for the ERA-Interim period 1979-2010. Grid points with a significant correlation are dotted ( $t$-test, 95\% confidence level). (b) RMSE of annual $E_{\text {out }}$ time series of SDD relative to $\mathrm{DD}_{\text {era }}$ time series per CCLM grid point for the ERA-Interim period 1979-2010, normed by the standard deviation of $\mathrm{DD}_{\text {era }}$

their figure 3(g)). Although the magnitudes of the signals are somewhat weaker for SDD, regional trends of annual $E_{\text {out }}$ are the same as in Hueging et al. (2013). Both, results of SDD and of Hueging et al. (2013), reveal increasing annual energy output over northern and northeast Europe and a decrease in $E_{\text {out }}$ over southern Europe. Similar results are observed for changes in $E_{\text {out }}$ during the winter months (December, January, February; see Figure 13(b)). Again, climate change signals as simulated by SDD are weaker than in Hueging et al. (2013, see their figure 3(i)), but regional patterns agree well in terms of the sign of the trend. Higher $E_{\text {out }}$ for 2061-2100 is observed over northern and central Europe, whereas less energy output is simulated for the Mediterranean countries. Clear regional differences between SDD and Hueging et al. (2013) occur only for the climate change signals of the summer months (June, July, and August). While Hueging et al. (2013) detected a positive trend of $E_{\text {out }}$ over the Baltic Sea (see their figure $3(\mathrm{k})$ ), reduced $E_{\text {out }}$ for 2061-2100 is simulated by SDD (Figure 13(c)). However, both methods reveal a decrease in $E_{\text {out }}$ for Germany, Poland, Great Britain, and most parts of the Mediterranean countries.

The advantage of SDD is that it can also be applied to other greenhouse gas scenarios. Climate change signals of B1 are weaker than for the A1B scenario (Figure 13(d)-(f)), as one would expect. Apart from that, both scenarios show similar regional trends by the end of the 21 st century, i.e. increasing $E_{\text {out }}$ over northern Europe and decreasing $E_{\text {out }}$ over southern Europe for the whole year and for the winter months, and a negative trend over central and western Europe for summer.

Regional changes of annual $E_{\text {out }}$ in the A2 scenario have the same magnitude as in the A1B scenario (Figure 13(g)). Interestingly, differences between both scenarios are stronger in terms of the intra-annual changes. While the trend of $E_{\text {out }}$ for the winter months is stronger in the A2 scenario over most parts of the central and northern Europe, in particular over Germany (Figure 13(h)), the decrease in $E_{\text {out }}$ for June, July, and August is slightly weaker than in the A1B scenario (Figure 13(i)).

Despite slight discrepancies in the climate change projections for the A1B scenario compared to Hueging et al. (2013), these results reveal that the proposed SDD is an adequate downscaling tool for the analysis of wind energy changes in large ensembles of climate change scenarios, providing results consistent to DD methods in a cost-efficient way.

\section{Summary and discussion}

In this study, a SDD approach for the analysis of regional changes of wind energy output in large ensembles of decadal prediction systems and long-term climate projections is proposed and evaluated for different data sets. Here, SDD has been generated for applications to central Europe with special focus on Germany, for which the weather typing approach has been performed.

Regarding the verification of the SDD methodology and the comparison to observational data, SDD is able to derive realistic near-surface wind distributions for most stations in Germany. Some deficits can be observed for coastal stations, where simulated and observed PDFs of 10-m wind velocities differ. These discrepancies may in part be associated with the resolution of the model chain. At a horizontal resolution of $0.22^{\circ}(\sim 25 \mathrm{~km})$, grid cells that correspond to stations at the coasts consist of not only land surfaces but also ocean surfaces, thus comprising unrealistic surface characteristics. Results for coastal areas would be improved by increasing the horizontal resolution of the simulated representative episodes by, for example, using a double nesting procedure. Despite these deficits, we conclude that SDD simulates realistic near-surface wind speeds and regional $E_{\text {out }}$ patterns for recent climate conditions, and provides comparable results to the time-consuming pure DD approach. This assessment is valid for the entire European sector.

Regarding the application of SDD to decadal hindcasts, a good accordance between the SDD approach and DD 

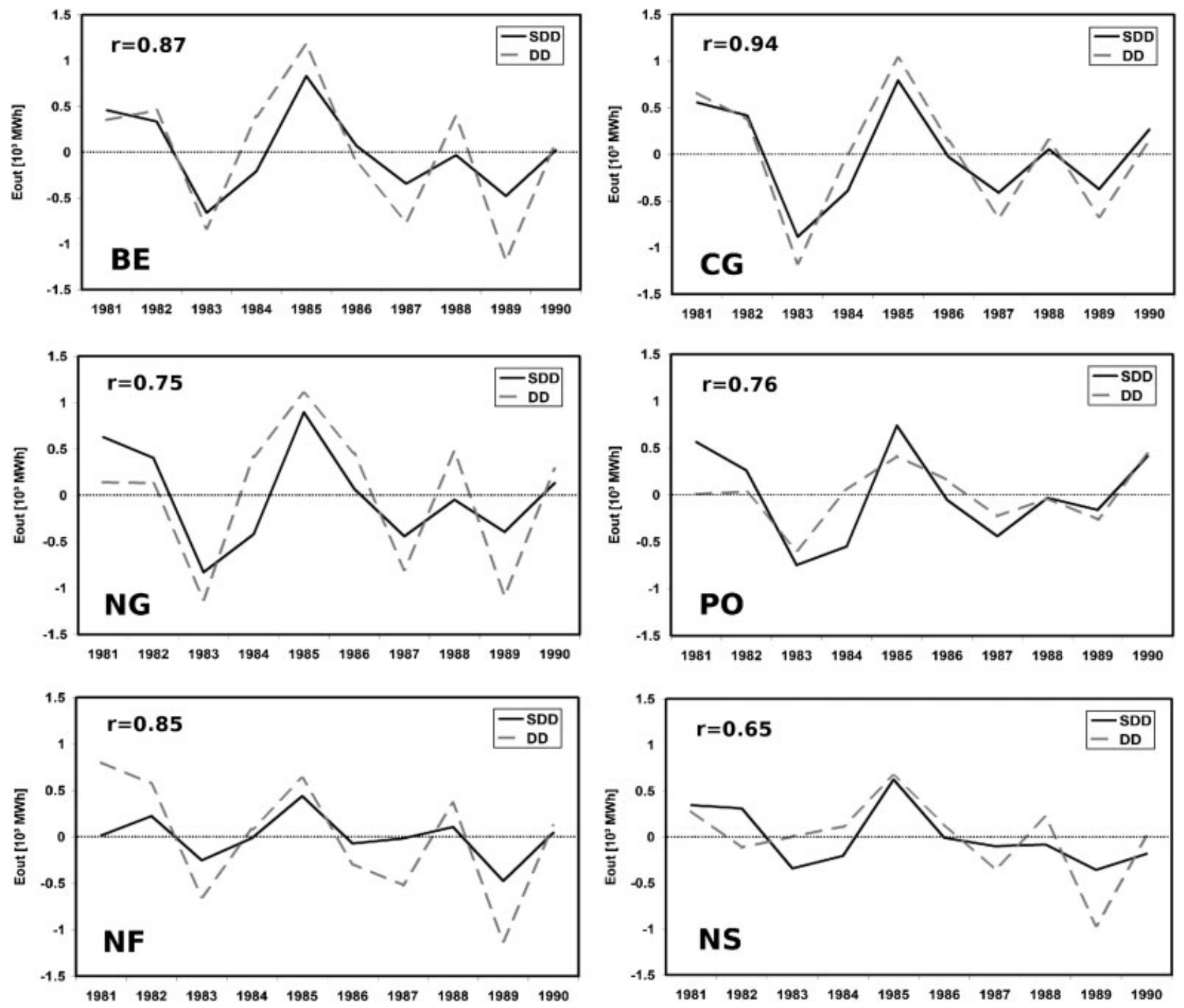

Figure 10. Time series of annual $E_{\text {out }}$ anomalies in $10^{3}$ MWh for the first realization of dec1980 (1981-1990) as obtained by SDD (black solid line) and by $\mathrm{DD}_{1980 \_1}$ (grey dashed line) for sub-regions in Belgium (BE), central Germany (CG), northern Germany (NG), Poland (PO), northern France (NF), and the North Sea (NS). For location of the sub-regions, see Figure 7(a). The correlations between SDD and DD time series are given in the upper left corner of each panel.

methods on timescales down to single years is found for Germany and nearby areas, particularly Poland, Czech Republic, and the Benelux countries. For four exemplary decadal hindcasts, high correlations between SDD- and DD-simulated annual $E_{\text {out }}$ time series are found for these onshore areas. Lower correlations are detected for other European countries (e.g. France and Scandinavia) and for offshore areas, which implies that the applicability of SDD for decadal prediction systems as used in this study is limited to Germany and the surrounding countries. This is due to the considered weather typing approach that is representative for the large-scale flow over an area of roughly $20^{\circ}$ by $30^{\circ}$ centred over Germany (see Figure 2 ). The approach could also be applied for decadal predictions of wind energy in other regions of Europe simply by choosing different central points for the CWT classification, e.g. in Scandinavia or in southern Europe. For Germany and nearby areas, annual $E_{\text {out }}$ time series as obtained by SDD show a slightly lower variability than DD-simulated time series. The consequences of this deficit for the detection of a predictive skill of decadal hindcasts (e.g. in terms of anomaly correlations) can be considered negligible, as for almost every year SDD simulates similar anomalies as DD in terms of the sign of $E_{\text {out }}$, as this effect can be easily scaled up. SDD has been employed to downscale the full ensemble of MPI-ESM that comprises 520 decadal hindcasts and predictions of a length of 10 years. Assuming a simulation time of $\sim 5$ days per hindcast when using transient simulations with RCMs even on fast supercomputers, the regionalization of such a large ensemble can hardly be accomplished by purely DD methods. SDD, therefore, forms a suitable tool to analyse the predictive skill of decadal prediction systems with respect to wind energy on regional scales.

In this study, simulated representative days of the 77 classes have been forced with ERA-Interim. In a sensitivity study, we have repeated the procedure as applied to decadal hindcasts with a new set of representatives using 

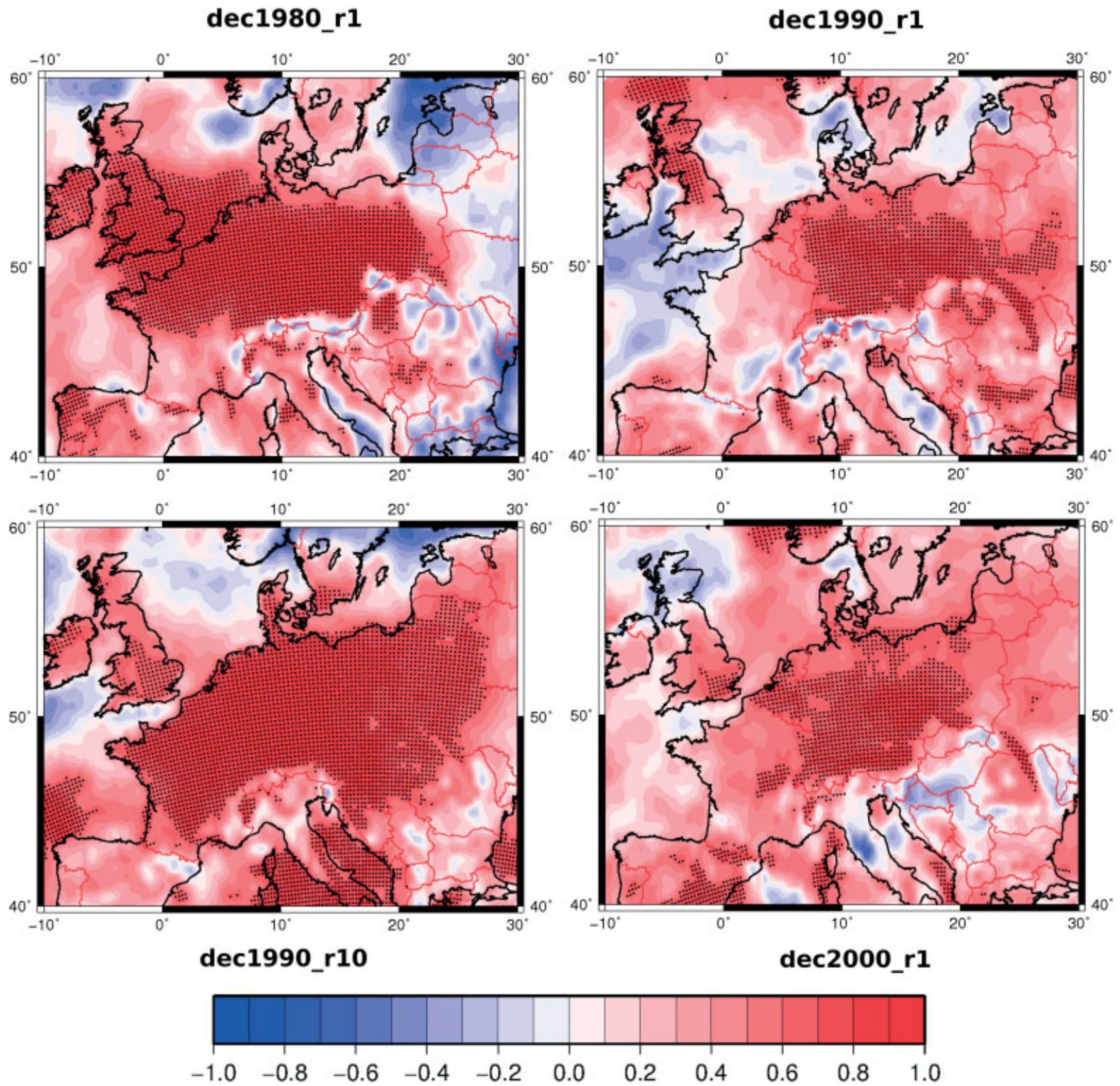

Figure 11. Correlation per CCLM grid point between annual $E_{\text {out }}$ time series simulated by SDD and by DD for exemplary hindcasts dec1980_r1 (1981-1990), dec1990_r1 (1991-2000), dec1990_r10 (1991-2000), and dec2000_r1 (2001-2010). Grid points with a significant correlation are dotted ( $t$-test, $95 \%$ confidence level).

large-scale fields of the MPI-ESM as boundary conditions. For Germany and nearby areas, results of the sensitivity study are quite similar to the results presented in this paper (e.g. annual $E_{\text {out }}$ time series). Hence, the SDD method seems to be quite robust and the downscaled ERA-Interim-forced representatives used in this study can also be employed for the application of SDD to decadal prediction systems of other institutions contributing to CMIP5.

Regarding climate change applications, the SDD method performs well for the entire European sector, including Scandinavia and southern Europe. For example, long-term climate change projections of wind energy potentials as obtained by SDD agree well to the results of other studies using DD methods, with mean annual wind energy increasing over countries in northern Europe and decreasing over southern Europe in a future climate (cf. Hueging et al., 2013). Furthermore, several studies reveal positive trends over the regions in northern Europe for future winter months and a decline in wind energy during the summer months (Nolan et al., 2012; Hueging et al., 2013), which is consistent with the findings of this study. These results suggest that ten representatives per class (see also Appendix S1) are sufficient to cover the main spectrum of potential European-wide spacious wind patterns that may occur within a class in climatological time periods. Compared to Hueging et al. (2013), the climate change signals of SDD are slightly weaker for most parts of Europe, hence the magnitude of the wind energy trends as simulated by SDD should be regarded with care. Here, 

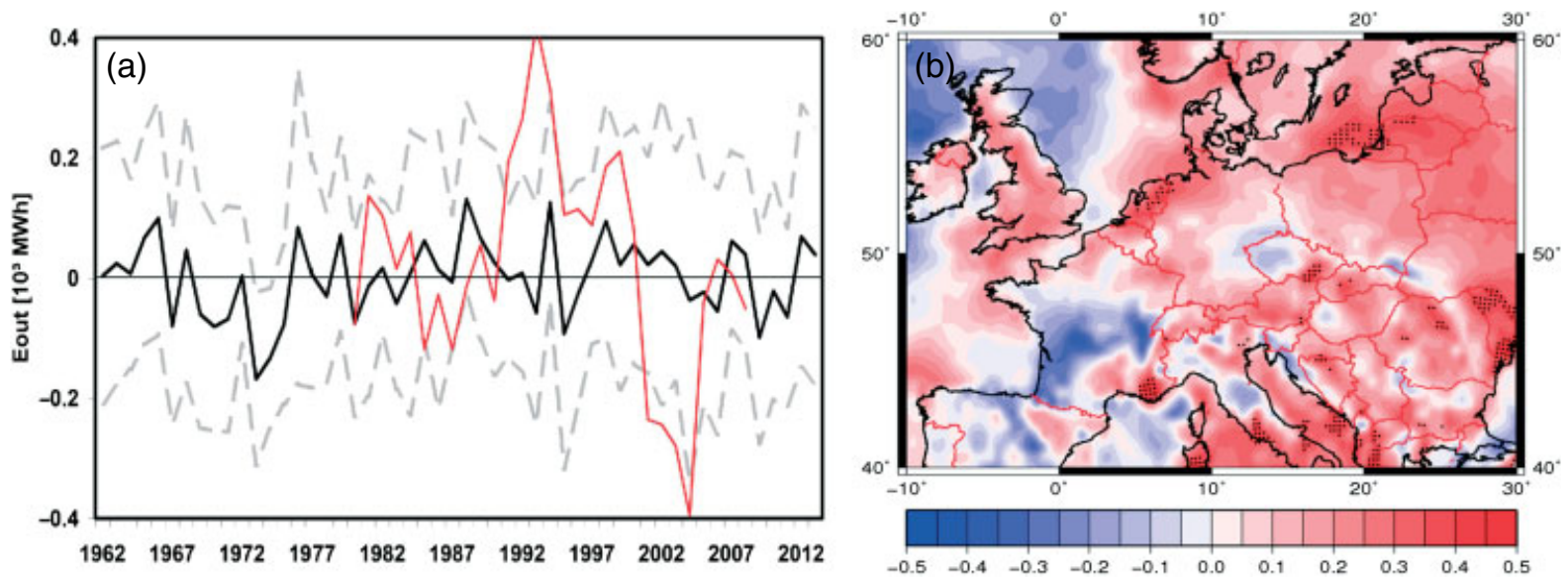

Figure 12. (a) Four-year running mean time series of $E_{\text {out }}$ for years $1-4$ after initialization for the MPI-ESM decadal hindcasts and predictions from dec1960 to dec2011 as obtained by the SDD method for a sub-region in central Germany (cf. Figure 7(a)). Shown is the ensemble mean over the ten realizations (black solid line), and the ensemble mean $\pm 1 \mathrm{SD}$ of the ten ensemble members (grey dashed line). The thin grey line shows the 4-year running mean time series of $\mathrm{DD}_{\text {era. }}$ (b) Correlation between the 4-year running mean time series of $\mathrm{DD}_{\text {era }}$ (thin grey line in (a)) and of the MPI-ESM ensemble mean for years 1-4 after initialization (black solid line in (a)). Grid points with a significant correlation are dotted ( $t$-test, $95 \%$ confidence level).

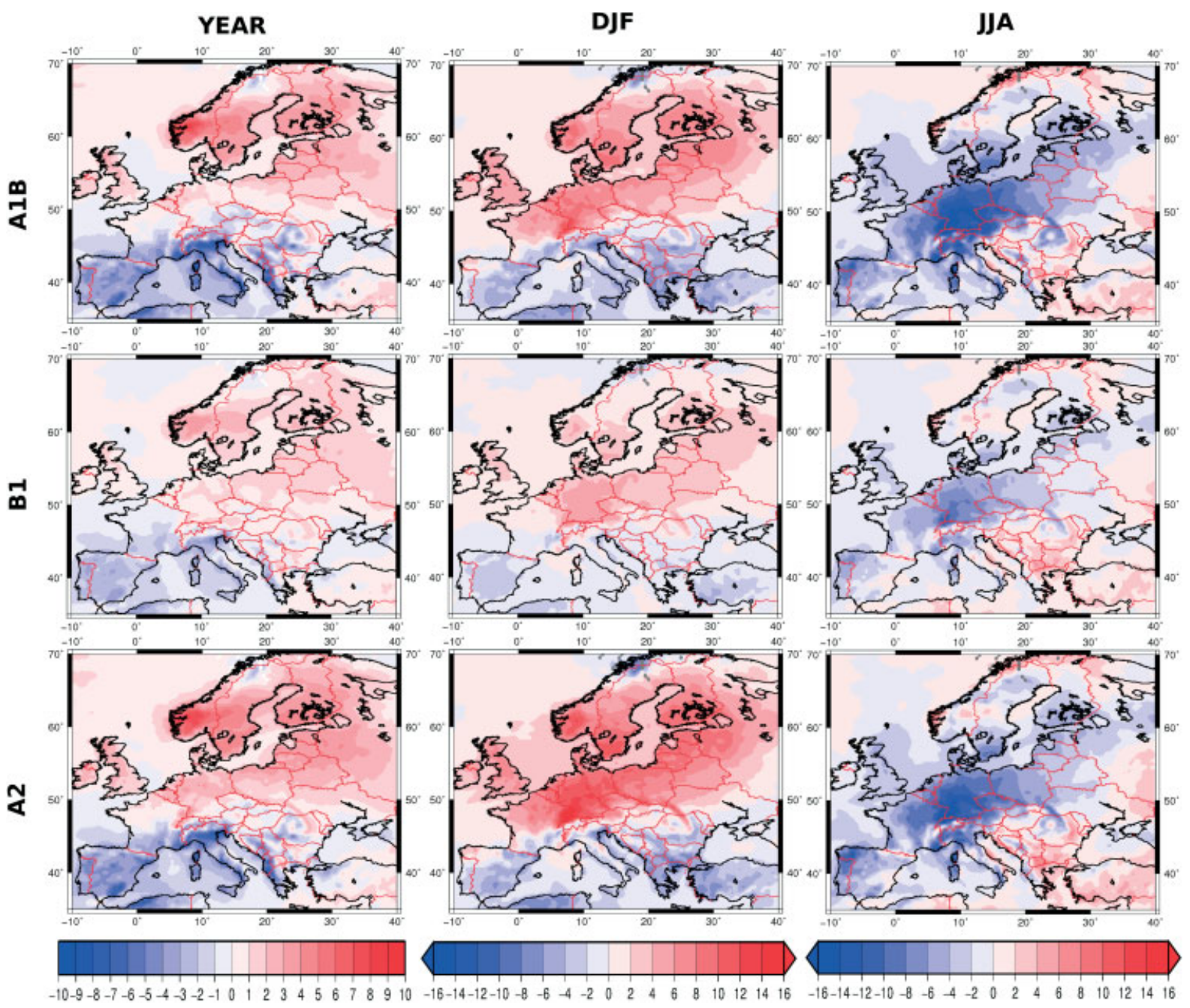

Figure 13. Regional changes (\%) in $E_{\text {out }}$ between ECHAM5 SRES (2061-2100) and the ECHAM5 20C scenario (1961-2000) as obtained by SDD for all year (annual, left column), winter (DJF, middle column), and summer (JJA, right column). Differences are shown for ensemble means of the first two realizations of the scenarios A1B (upper row), B1 (middle row), and A2 (lower row). 
SDD has been employed to SRES of the GCM ECHAM5. As its application to other data sets requires only a new employment of the CWT analysis on global MSLP fields, while the other steps of the downscaling procedure are in principle the same as for ECHAM5, SDD can easily be applied to other GCMs. This enables an assessment of the uncertainty of long-term climate change projections that may arise not only from different scenarios but also from different GCMs. SDD is therefore an adequate tool to analyse regional wind energy changes in multi-model ensembles such as those released in the new CMIP5 (Taylor et al., 2012), which includes current GCM data of 29 institutions.

We conclude that SDD is a suitable and inexpensive alternative to DD and that it can be easily applied for large ensemble of global runs. Although the current application focused on wind energy potentials for Germany, decadal hindcasts and climate change projections, the methodology has the potential for use in many other applications. Another potential valuable application could be, for example, the investigation of changes of surface wind percentiles in near- and long-term future. As PDFs of $10 \mathrm{~m}$ winds are computed in the third step of SDD (see Section 2), the same procedure and simulated representatives as used in this study could be employed for this purpose.

The here presented SDD methodology has been developed primarily for applications within the ongoing MiKlip consortium ('Mittelfristige Klimaprojektion', http://www.fona-miklip.de) and a detailed analysis of the forecast skill of the MPI-ESM decadal prediction system with respect to wind energy on the regional scale is still ongoing. With this aim, different deterministic and probabilistic metrics (see, for example, Goddard et al., 2013) for estimating the predictive skill and the forecast uncertainty will be employed.

\section{Acknowledgements}

This research was supported by the German Federal Ministry of Education and Research (BMBF) under the project Probabilistic Decadal Forecast for central and western Europe (MiKlip -PRODEF, contract 01LP1120A), which is part of the MiKlip consortium ("Mittelfristige Klimaprojektion", http://www.fona-miklip.de). We thank the ECMWF for the ERA-Interim Reanalysis data set and the DWD for providing the wind speed data. We acknowledge the Max-Planck-Institute (Hamburg, Germany) for providing the GCM (ECHAM5 and MPI-ESM). We thank the German Climate Computer Centre (DKRZ, Hamburg) for computer and storage resources (project number 785 PRODEF). We thank the COSMO-CLM community and the members of MIKLIP-Module C (Regionalization) for discussions. We also thank Patrick Ludwig, Rabea Haas, and Hanna Hueging (University of Cologne) for discussions. Finally, we would like to thank the two anonymous reviewers for their helpful comments.

\section{Supporting Information}

The following supporting information is available as part of the online article:

Appendix S1. Sensitivity of the SDD to the number of simulated representatives.

Figure S1. PDFs of $10-\mathrm{m}$ wind velocity for the period 1979-2010 at the two exemplary CCLM grid points corresponding to the stations Bremen (BR) and Stuttgart (ST). Thin black line: $\mathrm{DD}_{\text {era }}$. Blue line: SDD with five simulated representative days per weather class (5repr). Red line: SDD with ten simulated representative days per weather class (10repr). Green line: SDD with 20 simulated representative days per weather class (20repr). Locations of the stations are shown in Figure 5(a).

\section{References}

Balmaseda MA, Mogensen K, Weaver AT. 2013. Evaluation of the ECMWF ocean reanalysis system ORAS4. Q. J. R. Meteorol. Soc. 139: $1132-1161$.

Dee DP, Uppala SM, Simmons AJ, Berrisford P, Poli P, Kobayashi S, Andrae U, Balmaseda MA, Balsamo G, Bauer P, Bechtold P, Beljaars ACM, van de Berg L, Bidlot J, Bormann N, Delsol C, Dragani R, Fuentes M, Geer AJ, Haimberger L, Healy SB, Hersbach H, Holm EV, Isaksen L, Kallberg P, Kohler M, Matricardi M, McNally AP, Monge-Sanz BM, Morcrette JJ, Park BK, Peubey C, de Rosnay P, Tavolato C, Thepaut JN, Vitart F. 2011. The ERA-Interim reanalysis: configuration and performance of the data assimilation system. $Q$. $J$. R. Meteorol. Soc. 137: 553-597.

EEA. 2009. Europe's onshore and offshore wind energy potential: an assessment of environmental and economic constraints. EEA Tech. Rep. 6/2009, European Environmental Agency, Copenhagen, 88 p.

Fuentes U, Heimann D. 2000. An improved statistical-dynamical downscaling scheme and its application to the Alpine precipitation climatology. Theor. Appl. Climatol. 65: 119-135.

General Electric. 2010. 2.5 MW wind turbine series. GE Brochure GEA17007B, General Electric, Fairfield, CT, 16 p, http://www.geen ergy.com/content/multimedia/_files/downloads/GEA17007AWind25 Brochure.pdf.

Giorgi F, Jones C, Asrar GR. 2006. Adressing climate information needs at the regional level: the CORDEX framework. Bull. World Meteorol. Organ. 58: $175-183$.

Goddard L, Kumar A, Solomon A, Smith D, Boer G, Gonzale P, Kharin V, Merryfield W, Deser C, Mason SJ, Kirtman BP, Msadek R, Sutton R, Hawkins E, Fricker T, Hegerl G, Ferro CAT, Stephenson DB, Meehl GA, Stockdale T, Burgman R, Greene AM, Kushnir Y, Newman M, Carton J, Fukumori I, Delworth T. 2013. A verification framework for interannual-to-decadal predictions systems. Clim. Dyn. 40: $245-272$.

Harvey BJ, Shaffrey LC, Woollings TJ, Zappa G, Hodges KI. 2012. How large are projected 21st century storm track changes? Geophys. Res. Lett. 39: L18707, DOI: 10.1029/2012GL052873.

Hewitson BC, Crane RG. 1996. Climate downscaling: techniques and application. Climate Res. 7: 85-95.

Hueging H, Born K, Haas R, Jacob D, Pinto JG. 2013. Regional changes in wind energy potential over Europe using regional climate model ensemble projections. J. Appl. Meteorol. Climatol. 52: 903-917.

IEC. 2005a. Wind turbines - part 1: design requirements. IEC 61400-1, International Electrotechnical Commission. Geneva, Switzerland, 179 p.

IEC. 2005b. Wind turbines - part 3: design requirements for offshore wind turbines. IEC 61400-3, International Electrotechnical Commission. Geneva, Switzerland, $263 \mathrm{p}$.

Jenkinson AF, Collinson FP. 1977. An initial climatology of gales over the North Sea. In Synoptic Climatology Branch Memorandum, No. 62. Meteorological Office: Bracknell, UK.

Jones PD, Hulme M, Briffa KR. 1993. A comparison of lamb circulation types with an objective classification scheme. Int. J. Climatol. 13: 655-663.

Jones PD, Harpham C, Briffa KR. 2012. Lamb weather types derived from reanalysis products. Int. J. Climatol. 33: 1129-1139. 
Jungclaus JH, Keenlyside N, Botzet M, Haak H, Luo J-J, Latif M, Marotzke J, Mikolajewicz U, Roeckner E. 2006. Ocean circulation and tropical variability in the coupled model ECHAM5/MPI-OM. J. Clim. 19: $3952-3972$.

Lamb HH. 1972. British Isles weather types and a register of the daily sequence of circulation patterns 1981-1971. In Geophysical Memoir, No. 116. HMSO, 85 p: London.

Manwell JF, McGrown JG, Rogers AL. 2009. Wind Energy Explained, Theory, Design and Application, 2nd edn. Wiley, 704 p: Chichester, UK.

Maraun D, Wetterhall F, Ireson AM, Chandler RE, Kendon EJ, Goodess CM, Jones RG, Onof C, Vrac M, Thiele-Eich I. 2010. Precipitation downscaling under climate change: recent developments to bridge the gap between dynamical models and the end user. Rev. Geophys. 48 : RG3003, DOI: 10.1029/2009RG000314.

Merryfield WJ, Lee WS, Boer GJ, Kharin VV, Scinocca JF, Flato GM, Ajayamohan RS, Fyfe JC, Tang M, Polavarapu S. 2013. The Canadian Seasonal to Interannual Prediction System. Part I: models and initialization. Mon. Weather Rev. 141: 2910-2945.

Moccia J, Arapogianni A, Wilkes J, Kjaer C, Gruet R. 2011. Pure power - wind energy targets for 2020 and 2030. European Wind Energy Association Report, EWEA, Brussels, 98 p, http://www.ewea. org/fileadmin/files/library/publications/reports/Pure_Power_III.pdf.

Mueller WA, Baehr J, Haak H, Jungclaus JH, Kroeger J, Matei D, Notz D, Pohlmann H, von Storch JS, Marotzke J. 2012. Forecast skill of multi-year seasonal means in the decadal prediction system of the Max Planck Institute for Meteorology. Geophys. Res. Lett. 39: L22707, DOI: 10.1029/2012GL053326.

Najac J, Lac C, Terray L. 2011. Impact of climate change on surface winds in France using a statistical-dynamical donwscaling method with mesoscale modelling. Int. J. Climatol. 31: 415-430, DOI: 10.1002/joc. 2075 .

Nakicenovic N, Swart R. 2000. Emission scenarios. A Special Report of Working Group III of the Intergovernmental Panel on Climate Change, Cambridge University Press. Cambridge, UK, 599 p.

Nolan P, Lynch P, McGrath R, Semmler T, Wang SY. 2012. Simulating climate change and its effect on the wind energy resource of Ireland. Wind Energy 15: 593-608.
Ouammi A, Ghigliotti V, Robba M, Mimet A, Sacile R. 2012. A decision support system for the optimal exploitation of wind energy on regional scale. Renew. Energy 37: 299-309.

Pinto JG, Neuhaus CP, Leckebusch GC, Reyers M, Kerschgens M. 2010. Estimation of wind storm impacts over West Germany under future climate conditions using a statistical-dynamical downscaling approach Tellus A 62: 188-201, DOI: 10.1111/j.1600-0870.2009.00424.x.

Pryor SC, Barthelmie RJ. 2010. Climate change impacts on wind energy: a review. Renew. Sustain. Energy Rev. 14: 430-437.

Pryor SC, Schoof JT, Barthelmie RJ. 2005. Empirical downscaling of wind speed probability distributions. J. Geophys. Res. 110: D19109, DOI: 10.1029/2005JD005899.

Rockel B, Will A, Hense A. 2008. Special issue: regional climate modelling with COSMO-CLM (CCLM). Meteorol. Z. 17: 347-348.

Roeckner E, Brokopf R, Esch M, Giorgetta M, Hagemann S, Kornblueh L, Manzini E, Schlese U, Schulzweida U. 2006. Sensitivity of simulated climate to horizontal and vertical resolution in the ECHAM5 atmosphere model. J. Clim. 19: 3771-3791.

Solomon S, Qin D, Manning M, Chen Z, Marquis M, Averyt K, Tignor MMB, Miller JR, Eds HL. 2007. Climate Change 2007: The Physical Science Basis. Cambridge University Press: Cambridge, UK, 996 p.

Taylor KE, Stouffer RJ, Meehl GA. 2012. An overview of CMIP5 and the experiment design. Bull. Am. Meteorol. Soc. 93: 485-498.

Ulbrich U, Pinto JG, Kupfer H, Leckebusch GC, Spangehl T, Reyers M. 2008. Changing northern hemisphere storm tracks in an ensemble of IPCC climate change simulations. J. Clim. 21: 1669-1679.

Wilby RL, Wigley TML. 1997. Downscaling general circulation model output: a review of methods and limitations. Prog. Phys. Geogr. 21 : 530-548.

Wilkes J, Moccia J, Dragan M. 2012. Wind in power - 2011 European statistics. European Wind Energy Association Report, EWEA Brussels, $11 \mathrm{p}$, http://www.ewea.org/fileadmin/files/library/publicat ions/statistics/Wind_in_power_2011_European_statistics.pdf.

Woollings T, Gregory JM, Pinto JG, Reyers M, Brayshaw DJ. 2012. Response of the North Atlantic storm track to climate change shaped by ocean-atmosphere coupling. Nat. Geosci. 5: 313-317. 